\title{
Drying of Poloxamer Hydrogel Films
}

\author{
ZHIYONG GU, PASCHALIS ALEXANDRIDIS
}

Department of Chemical and Biological Engineering, University at Buffalo, The State University of New York, Buffalo, New York 14260-4200

Received 21 July 2002; revised 17 November 2003; accepted 18 November 2003

\begin{abstract}
The drying of hydrogel films formed by Poloxamer 407 poly(ethylene oxide)poly(propylene oxide)-poly(ethylene oxide) amphiphilic block copolymer was investigated at various air relative humidity $(\mathrm{RH})$ conditions ranging from 11 to $97 \%$. Initially, the amount of water lost increased linearly with the drying time. After this linear region (stage I), a nonlinear behavior was observed (stage II). The drying rate increased with decreasing $\mathrm{RH}$, thus greatly shortening the drying time. A decrease of the film thickness also shortened the drying time; however, the drying mechanism did not change. Three models for one-dimensional water diffusion were used to fit the experimental results at different $\mathrm{RH}$ conditions and film thicknesses. Model 1 assumes semi-infinite medium and constant diffusion coefficient, and fits very well the data in stage I of the drying process. The fitted water diffusion coefficient $(D)$ is $5 \times 10^{-10} \mathrm{~m}^{2} / \mathrm{s}$, whereas the effects of the RH are captured by a proportionality constant $(\alpha)$ that appears in the boundary condition. Model 2 considers a finite (constant) film thickness and captures the experimental observations over the whole drying period for the same $D$ and $\alpha$ as in Model 1 . The analytical solutions available for Models 1 and 2, used together with the experimentally derived model parameters $D$ and $\alpha$, allow for easy estimation of drying time and water loss from Poloxamer hydrogel films of various compositions and thicknesses and at different relative humidities. Numerical solutions for water diffusion under conditions of decreasing film thickness and diffusion coefficient being a function of concentration are also presented (Model 3). It becomes apparent from the fit of the data to the different models that the drying rate is more sensitive to the boundary condition at the film-air interface (represented by $\alpha$ ) than to the diffusion in the film. It is notable that the $\alpha$ values obtained from the fits of the Poloxamer hydrogel drying rate are comparable to those obtained from drying of water films under the same experimental conditions. ( 2004 Wiley-Liss, Inc. and the American Pharmacists Association J Pharm Sci 93:1454-1470, 2004
\end{abstract}

Keywords: amphiphilic block copolymer; drying; evaporation; diffusion; ordered structures; Poloxamer

\section{INTRODUCTION}

Polymer-based films are frequently encountered in the pharmaceutical and biomedical fields, for example, coatings on solid dosage forms, ${ }^{1-11}$ packaging, ${ }^{11}$ cosmetic emulsions and gels applied to skin, ${ }^{12-14}$ and pharmaceutics applied to mucus

Correspondence to: Paschalis Alexandridis (Telephone: 716-645-2911; Fax: 716-645-3822;

E-mail: palexand@eng.buffalo.edu)

Journal of Pharmaceutical Sciences, Vol. 93, 1454-1470 (2004)

(c) 2004 Wiley-Liss, Inc. and the American Pharmacists Association surfaces. ${ }^{15-17}$ Many film formation processes involve solvent evaporation (drying) from a polymer solution or dispersion. As the solvent is removed from the polymer solution, the structure of the polymer may change dramatically, for example, from randomly dissolved polymers to (semi) crystalline structures, or from colloidal dispersion to continuous film. The types of structures that the polymers attain over the course of drying should affect both the solvent and the drug diffusion coefficient in the film. Drying is also a critical step in the preparation of many pharmaceutical products. For example, solid dosage forms 
(granules, tablets, or films) are often prepared by solvent cast (evaporation) method, in which water (or organic solvent, or mixture of them) is evaporated and a dry dosage form is achieved. ${ }^{2,18-20}$ Solid dosage forms can also be prepared by spraydrying method. ${ }^{6,21}$ The drying methods and drying conditions have a profound effect on the structure and physico-mechanical properties of the final dosage forms, and thus affect the migration and release of drugs in the dosage forms. ${ }^{22-37}$

A class of polymers that find numerous applications in the pharmaceutical and biomedical fields, for example, drug formulation and delivery, ${ }^{38-43}$ are the Poloxamers. In the presence of water, Poloxamer or Pluronic poly(ethylene oxide)-poly (propylene oxide)-poly(ethylene oxide) (PEO-PPOPEO) amphiphilic block copolymers exhibit a variety of ordered (lyotropic liquid crystalline) nanostructures, where spherical, cylindrical, or planar micelles are organized in a lattice. ${ }^{44-47}$ Many of the applications of Poloxamers involve the transport of solvent (water) in the block copolymer solutions and/or hydrogels. In controlled release applications, the transport of both water and drug molecules is often accompanied by the dissolution of Poloxamer hydrogels. ${ }^{41,48-50}$ Whereas the transport of solvent in disordered solutions of polymers or in semicrystalline polymers has been studied extensively, ${ }^{51-60}$ the transport of water in the nanostructured hydrogels formed by Poloxamers has not received appropriate attention.

In this work, we were interested in the removal of water from hydrogel films formed by Poloxamer 407. As the solvent concentration in the hydrogel decreases, the ordered structures will undergo a transition from micellar cubic phase to hexagonal phase. ${ }^{61-64}$ When the solvent (water) concentration is very low, crystallization of the PEO blocks of the copolymers will occur. ${ }^{61-64}$ These ordered structures may affect the drying mechanism of the hydrogels. Our study does not only improve the understanding of drying of films based on Poloxamer hydrogels, but is also relevant to other surfactant-containing film applications such as skin creams and surface cleaning. In this article, we first present experimental data on the time evolution of water loss from Poloxamer 407 block copolymer hydrogels when exposed to air of different relative humidities. We then fit the experimental data with models for water diffusion, and we obtain the diffusion coefficient of water in the hydrogel and a parameter that describes the effect of relative humidity $(\mathrm{RH})$ on evaporation. We finally compare the drying of Poloxamer 407 hydrogels to that of polyethylene glycol (PEG) aqueous solutions.

\section{MATERIALS AND METHODS}

\section{Materials}

The Poloxamer 407 (Pluronic F127 NF) poly (ethylene oxide)-block-poly(propylene oxide)block-poly(ethylene oxide) copolymer was used as received from BASF Corp (Mount Olive, NJ). It has nominal molecular weight of $12,600 \mathrm{~g} / \mathrm{mol}$ and 70 wt \% PEO content. On the basis of its molecular weight and chemical composition, Poloxamer 407 can be represented by the formula $(\mathrm{EO})_{100}(\mathrm{PO})_{70}(\mathrm{EO})_{100}$. Poly(ethylene glycol) homopolymers PEG4000 (molecular weight $=3500$ $\sim 4500 \mathrm{~g} / \mathrm{mol}$ ) and PEG20000 (molecular weight $=16,000 \sim 24,000 \mathrm{~g} / \mathrm{mol}$ ) were obtained from Fluka (Milwaukee, WI) and were used as received. Samples were prepared individually by weighing appropriate amounts of polymer and water with a Mettler AG245 (Toledo, OH) electronic balance with \pm 0.1 -mg accuracy. Lithium chloride $(\mathrm{LiCl})$, sodium bromide $(\mathrm{NaBr})$, sodium chloride $(\mathrm{NaCl})$, potassium chloride $(\mathrm{KCl})$, potassium nitrite $\left(\mathrm{KNO}_{3}\right)$, and potassium sulfate $\left(\mathrm{K}_{2} \mathrm{SO}_{4}\right)$ were purchased from Fisher Scientific (Suwanee, GA). All salts were analytical grade. Saturated aqueous salt solutions were prepared by dissolving a large excess amount of pure salts in water. Millipore-filtered water was used for all sample preparations.

\section{Generation of Known Constant Water Vapor Pressure}

The driving force for the solvent (water) transfer from one phase to another is the difference in the solvent chemical potential (or equivalently, osmotic pressure) between the different phases. In our case, when the water chemical potential in the block copolymer hydrogel (lyotropic liquid crystal) sample is less negative than that in the air, the hydrogel losses water, that is, drying takes place. When the water chemical potential in the hydrogel is more negative than that in the air, the hydrogel tends to absorb water. In our study, the water chemical potential at each air $\mathrm{RH}$ condition examined is higher than the water chemical potential in the initial hydrogel sample $(30 \mathrm{wt} \%$ Poloxamer 407), thus drying is achieved. When the water chemical potentials in each phase 
Table 1. Relative Humidity $(R H)$ and Water Chemical Potential $(\Delta \mu)$ of Saturated Aqueous Salt Solutions at $24^{\circ} \mathrm{C}$

\begin{tabular}{lcccccc}
\hline & \multicolumn{6}{c}{ Salt } \\
\cline { 2 - 7 } & $\mathrm{LiCl}$ & $\mathrm{NaBr}$ & $\mathrm{NaCl}$ & $\mathrm{KCl}$ & $\mathrm{KNO}_{3}$ & $\mathrm{~K}_{2} \mathrm{SO}_{4}$ \\
\hline$R H, \%^{a}$ & 11.3 & 57.9 & 75.4 & 84.6 & 93.8 & 97.4 \\
$\Delta \mu, \mathrm{J} / \mathrm{mol}$ & -5382 & -1350 & -699 & -413 & -157 & -66 \\
\hline
\end{tabular}

${ }^{a}$ These values are interpolated from Greenspan, ${ }^{66}$ where the relative humidity of saturated salt solutions is reported as a function of temperature.

become equal to each other, there is no net water transfer between the two phases and equilibrium is attained. The water chemical potential in the air, $\Delta \mu$, can be determined by the water vapor pressure in the air:

$$
\Delta \mu=R T \ln \left(\frac{p}{p_{0}}\right)=R T \ln (R H)
$$

The ratio of water vapor pressure $p$ to the saturated water vapor pressure $p_{0}$ is designated as relative humidity $(R H)$. Known water vapor pressures can be generated by saturated aqueous salt solutions. ${ }^{65,66}$ Table 1 lists the salts that we used to generate a series of known (constant) $\mathrm{RH}$ environments. The gel samples were equilibrated with air of known water vapor pressure in a large sealed Petri dish (diameter $\mathrm{D} \approx 140 \mathrm{~mm}$ ), with no direct contact between each hydrogel sample and the salt solutions. The saturated aqueous salt solutions and gel samples were each placed in small open Petri dishes (diameter $\mathrm{d} \approx 35 \mathrm{~mm}$ ). One large Petri dish contained eight small dishes, from which two dishes were gel samples and the other six dishes were salt solutions to ensure that a constant vapor pressure was maintained. Both large and small Petri dishes are made from hydrophobic material (polystyrene), so the absorption of water vapor by the dishes is negligible. Because the dishes are sealed well and there is no disturbance except when measurements are collected, the air is still and the air velocity is not a variable in these drying experiments.

The sealed dishes with the higher RH $(75,85$, 94, and 97\%) were placed in an incubator (kept at $24^{\circ} \pm 0.1^{\circ} \mathrm{C}$ ) that maintained a surrounding $\mathrm{RH}$ in the range $70-90 \%$. For the lower $\mathrm{RH}$ cases (11 and $58 \%$ ), the sealed dishes were kept in an airconditioned room with temperature at $24^{\circ} \mathrm{C}$ $\left( \pm 1^{\circ} \mathrm{C}\right)$ and $\mathrm{RH}$ ranging from 10 to $60 \%$. In this way, the disturbance of opening the system to take measurements was greatly shortened. The time needed for the system to reach the desired $\mathrm{RH}$ after disturbance was no more than half an hour. When the surrounding humidity and the desired humidity were similar, the equilibration time was very short (a few minutes). The time required for sample weighing was a few minutes, including the weighing time and sample transfer time. The time scale shown in the final results and data analysis is the real recording time, including the opening disturbance time and weight measurements time. Because the water loss in the early stages of the drying process was much larger than that in the final stages, the measurements were taken every 10-12 $\mathrm{h}$ in the beginning, and longer time intervals were used when the drying had proceeded. The total time required for drying ranged from 3 to 4 days for very dry air conditions $(11 \% \mathrm{RH})$ to about 60 days for very humid air conditions $(97 \% \mathrm{RH})$ (when the initial film thickness is $3 \mathrm{~mm})$. A digital hygrometer $( \pm 1.5 \% \mathrm{RH}$ accuracy; Fisher Scientific, Suwanee, GA) was used to check the RH of the air in contact with the saturated salt solutions.

\section{Hydrogel Film Formation}

The Poloxamer 407 sample exhibits a thermoreversible transition from liquid solution at low temperature (e.g., $4^{\circ} \mathrm{C}$ ) to ordered micellar cubic phase at room temperature. ${ }^{61-64}$ At $24^{\circ} \mathrm{C}$, the samples are isotropic solutions $\left(\mathrm{L}_{1}\right)$ below $18 \mathrm{wt} \%$ Poloxamer 407. Above 18 wt \% Poloxamer 407, various ordered structures form with increasing block copolymer concentration. ${ }^{61-64}$ When the block copolymer concentration is between 19 to $63 \mathrm{wt} \%$, a micellar cubic liquid crystal phase $\left(\mathrm{I}_{1}\right)$ exists at the temperature of our experiments $\left(24^{\circ} \mathrm{C}\right)$, in which the micelles are crystallized in a cubic lattice. When the concentration is in the range 65-75 wt \%, a hexagonal liquid crystalline phase $\left(\mathrm{H}_{1}\right)$ forms with structure consisting of cylindrical assemblies packed in a hexagonal lattice. At concentrations $>75$ wt $\%$, the block copolymer is in a semicrystalline paste-like form. 
The initial concentration of Poloxamer 407 samples studied here was set at $30 \mathrm{wt} \%$.

To prepare the 30 wt \% Poloxamer hydrogel, the block copolymer was mixed with water and kept in a refrigerator $\left(4^{\circ} \mathrm{C}\right)$ for several days until a homogeneous solution was obtained. To achieve a uniform film, the 30 wt \% Poloxamer 407 sample was first weighted in a small Petri dish, then moved to the refrigerator $\left(4^{\circ} \mathrm{C}\right)$ and kept there for a while. After the gel sample became liquid, the Petri dish container was moved out carefully and placed on a flat surface. Upon a slow increase in temperature, a uniform and smooth film of transparent gel was formed. The sample was weighed again to check for possible water loss during this process. Because the time required for film formation was generally about $10 \mathrm{~min}$, the water loss was negligible. The small container was then moved into the large dish that contained small containers with saturated salt solution. The large container was sealed carefully and the recording of time started.

We examined films of three different initial thicknesses $(1,3$, and $5 \mathrm{~mm}$ ) in order to access the effect of film thickness on the drying course of Poloxamer hydrogels. The 3-mm film thickness was used for all the air RH conditions, whereas 1-, $3-$, and $5-\mathrm{mm}$ films were examined at 58 and $85 \%$ relative humidities. The flat hydrogel film was initially transparent. The film surface receded toward the bottom of the container during the drying process. When the water content in the gel was low (about $20 \mathrm{wt} \%$ ), the hydrogel became opaque because of the semicrystalline domains formed by the PEO blocks of Poloxamer 407. This change in appearance coincides with the phase boundary between the hexagonal phase and the high-polymer-content paste phase. At this point, the film surface was no longer smooth but showed some wrinkles. The Poloxamer 407 concentration and water loss as a function of time data reported in the Results and Discussion section are the average values of two sets of experiments, con-

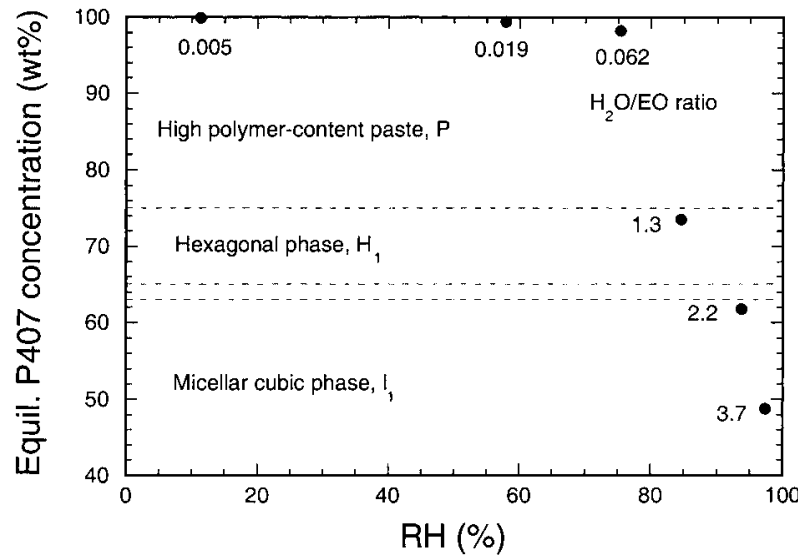

Figure 1. Equilibrium concentration (wt \%) of Poloxamer 407 in the hydrogel film as a function of the $\mathrm{RH}$ of the air in contact with the film. The values next to the data points indicate the water/EO molar ratio at equilibrium. The dotted lines indicate the Poloxamer 407 concentration where the ordered structure changes.

ducted in parallel at the same temperature and same air RH. Very good reproducibility was observed: the errors were generally below $1 \%$ (the maximum error was $3.2 \%$ ) and the error bars are smaller than the symbols used in the figures.

\section{RESULTS AND DISCUSSION}

\section{Equilibrium Water Content in Poloxamer Hydrogels}

When the chemical potential of water in the humid air that surrounds the Poloxamer hydrogels is equal to that of water in the hydrogels, then there is no net water transfer between the water vapor and the hydrogel, and equilibrium is achieved. Depending on the $\mathrm{RH}$, the equilibrium concentrations of Poloxamer hydrogels are different (see Fig. 1), and correspond to different ordered structures. ${ }^{67}$ Table 2 lists the equilibrium concentration and the hydration level $\left(\mathrm{H}_{2} \mathrm{O} / \mathrm{EO}\right.$ molar ratio) of Poloxamer 407 hydrogels at

Table 2. Equilibrium Concentration of Poloxamer 407 in the Hydrogel and Hydration Numbers $\left(\mathrm{H}_{2} \mathrm{O}\right.$ Molecules per EO Segments) at Different Relative Humidity $(R H)$ Conditions

\begin{tabular}{lcccccc}
\hline & \multicolumn{6}{c}{$R H, \%$} \\
\cline { 2 - 7 } & 11.3 & 57.9 & 75.4 & 84.6 & 93.8 & 97.4 \\
\hline P407 wt \% & 99.86 & 99.45 & 98.26 & 73.53 & 61.75 & 48.75 \\
$\mathrm{H}_{2}$ O/EO ratio & 0.005 & 0.019 & 0.062 & 1.3 & 2.2 & 3.7 \\
\hline
\end{tabular}


different relative humidities. These values are very relevant to the drying experiments because they correspond to the infinite time conditions.

Various ordered structures can form during the drying process. Because the initial concentration of the gel sample is $30 \mathrm{wt} \%$ Poloxamer 407, during the drying course, the micellar cubic and hexagonal liquid crystalline phases will successively form. At low relative humidities $(\leq 75 \%)$, the block copolymer hydrogel retains very low water content ( $\leq 2 \mathrm{wt} \%$ ), and thus contains crystalline PEO (as attested by the opacity of the film and irregularities on the surface). For example, the water content is only $0.14 \mathrm{wt} \%$ at $11 \% \mathrm{RH}$. The $\mathrm{H}_{2} \mathrm{O} / \mathrm{EO}$ molar ratio in this condition is only 0.005 , which indicates that the hydration level even in the hydrophilic PEO-rich domains is very low. When the $\mathrm{RH}$ of the air increases to $75 \%$, the water content increases, but is still very low, about $1.7 \mathrm{wt}$ $\%\left(\mathrm{H}_{2} \mathrm{O} / \mathrm{EO}\right.$ molar ratio $=0.062$, corresponding to the high polymer-content paste region in the phase diagram). When the $\mathrm{RH}$ increases to $85 \%$ or higher, the equilibrium water content in the Poloxamer hydrogels increases accordingly (see Table 2). For example, at $85 \% \mathrm{RH}$, the $\mathrm{H}_{2} \mathrm{O} / \mathrm{EO}$ molar ratio is 1.3 and the Poloxamer 407 concentration $73.5 \mathrm{wt} \%$ (corresponding to the hexagonal phase); at $97 \% \mathrm{RH}$, the $\mathrm{H}_{2} \mathrm{O} / \mathrm{EO}$ ratio equals 3.7 and the Poloxamer 407 concentration equals 48.8 wt $\%$ (micellar cubic phase).

\section{Time Evolution of Water Loss in Poloxamer Hydrogels}

Figure 2a shows the evolution of the Poloxamer 407 concentration as a function of time. This concentration is the average over the whole film, and is calculated based on mass balance at any given time. At first, the block copolymer concentration increased quickly; however, the change of the block copolymer concentration slowed down and then a plateau appeared. The weight of water lost from the film increases initially linearly with the drying time; after this linear region (stage I), a nonlinear behavior is observed (stage II; see Fig. 2b). Higher RH increased the time needed for the water weight loss, but in all the air $\mathrm{RH}$ conditions, the water weight loss increased linearly with the time initially. The linear region and nonlinear region in the water weight loss versus time curves (Fig. 2b) follow the two-stage mechanism for the drying process observed by many researchers. ${ }^{68-73}$ Although polymer entanglement and water hydration in the block copolymer
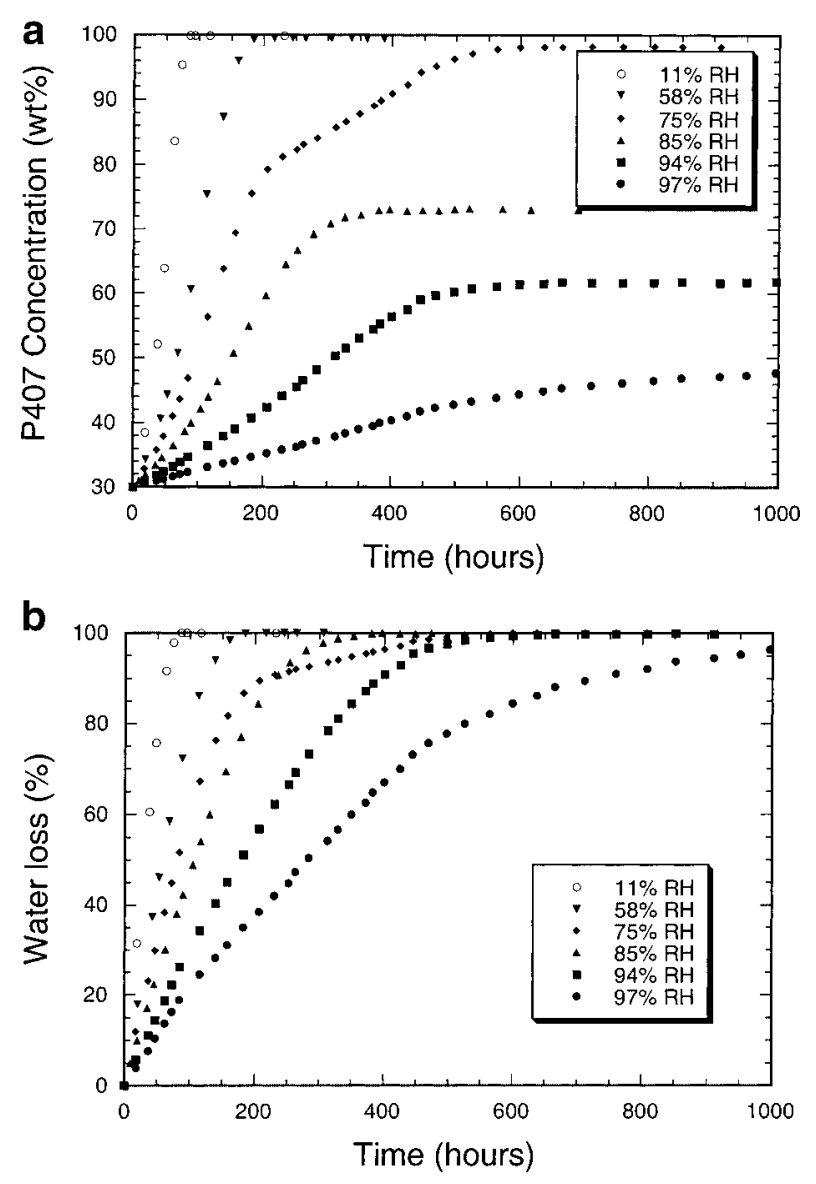

Figure 2. (a) Average Poloxamer 407 block copolymer concentration (wt \%) in the hydrogel film versus drying time at different $\mathrm{RH}$ values. (b) Percentage of water loss versus drying time at different $\mathrm{RH}$ values.

hydrogels will hinder the water transport in the hydrogel, ${ }^{74,75}$ initially the water content in the hydrogel is very high $\left(70 \mathrm{wt} \% \mathrm{H}_{2} \mathrm{O}\right)$ and water can move relatively freely. So the drying process in stage $\mathrm{I}$ is limited by the water evaporation at the film surface. When the time proceeds and the water concentration becomes low, polymer structure (entanglement or crystallinity) and hydration will have a more important role and both surface evaporation and water transport in the structured gel affect the drying rate. This corresponds to stage II of drying.

The drying rate, the derivative of the water loss versus time curve (Fig. 2b), is plotted in Figure $3 \mathrm{a}$ as a function of time. For all the air $\mathrm{RH}$ conditions, as described before, the drying rate is constant initially (stage I), followed by a falling rate region (stage II). The drying rate in stage I of the drying process is a linear function of air RH (Fig. 3b). The drying rate at stage $\mathrm{I}$ is $33.7 \mathrm{~g} /\left(\mathrm{m}^{2} \cdot \mathrm{h}\right)$ at $11 \% \mathrm{RH}$ 

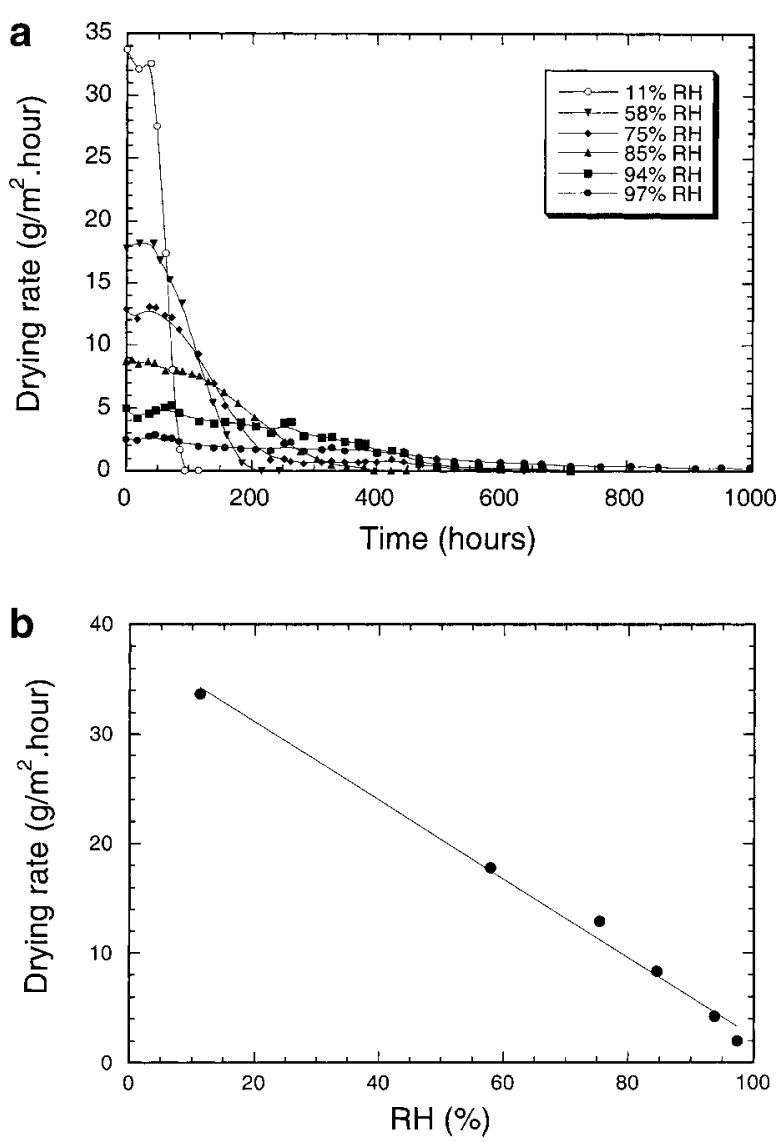

Figure 3. (a) Drying rate versus drying time at different $\mathrm{RH}$ values. (b) Drying rate at stage I as a function of $\mathrm{RH}$.

(when the initial film thickness is $3 \mathrm{~mm}$ ), but when the $\mathrm{RH}$ increases to $97 \%$, the drying rate decreases to $2 \mathrm{~g} /\left(\mathrm{m}^{2} \cdot \mathrm{h}\right)$, about 17 times smaller than the rate at $11 \% \mathrm{RH}$. The time duration of the constant rate region is longer when the $\mathrm{RH}$ is higher. At $11 \% \mathrm{RH}$, the total drying time is about $86 \mathrm{~h}$, but at $97 \% \mathrm{RH}$, the total drying time increases to $1420 \mathrm{~h}$ (about 60 days). To compare the stage I drying rate of Poloxamer hydrogel to evaporation of pure water, water films were dried using the same methodology and conditions as the Poloxamer films at relative humidities in the range of $11-58 \%$. We found the evaporation rate of pure water to be comparable to (slightly higher than) that of the gel in stage I drying at the same RH conditions. Fletcher and coworkers studied by a gravimetric technique the evaporation rate of water from various media, for example, pure liquid, ${ }^{76}$ emulsions, ${ }^{77}$ and structured and nonstructured liquid mixtures. ${ }^{78}$ Their results indicate that the initial water evaporation rate from pure water is constant at fixed temperature, and the evaporation rate is proportional to the vapor pressure of the sample, similar to the results obtained in our study in the stage I drying and pure water evaporation.

An additional feature is observed in stage II for drying at $75 \% \mathrm{RH}$, where the linear water loss versus time region is followed by a region where the water loss is linear to the square root of time, and then followed by a plateau. We believe that this behavior is due to the slowing down of diffusion in the film because of the formation of crystalline domains. The equilibrium Poloxamer content at $75 \% \mathrm{RH}$ falls in the paste-like phase, whereas that at $85 \% \mathrm{RH}$ falls in the hexagonal phase (Fig. 1). This is also consistent to observations on the drying of PEG (to be discussed later). We would expect the square root of time dependence to be present also in the drying of Poloxamer hydrogel at $\mathrm{RH}<75 \%$ (we have data for drying at $11 \%$ and $58 \% \mathrm{RHs}$ ); however, drying occurs much faster at these $\mathrm{RH}$ conditions and the time resolution of our data is not sufficient to establish this.

\section{Water Diffusion}

The diffusion of water in the hydrogel film can be described by Fick's second law ${ }^{79}$ :

$$
\frac{\partial C}{\partial t}=\frac{\partial}{\partial x}\left(D \frac{\partial C}{\partial x}\right)
$$

where $C$ is the concentration of water in the hydrogel, $\mathrm{g} / \mathrm{m}^{3} ; t$ is drying time; $x$ is the water diffusion direction (normal to the surface of the film); $D$ is the diffusion coefficient of water in the gel that is generally a function of the water concentration.

Because there is a large water vapor source (large amount of saturated aqueous salt solutions) in the sealed container where we kept the hydrogel film for drying, the water vapor pressure in contact with the polymer film is considered constant at all times. The rate of water exchange between the water vapor and the hydrogel sample depends on the $\mathrm{RH}$ of the air and the water concentration at the surface of the hydrogel. ${ }^{79}$ The simplest assumption is that the rate of water concentration change at the film surface is directly proportional to the difference between the actual concentration, $C_{s}$, at the surface at any time, and the concentration at the surface, $C_{\infty}$, in equilibrium with the (constant) water vapor pressure in the air. ${ }^{79}$

$$
-D \frac{\partial \mathrm{C}}{\partial x}=\alpha\left(C_{\infty}-C_{s}\right)
$$


where $\alpha$ is a constant of proportionality (related to the mass transfer coefficient between the film surface and the adjacent air). Equation 3 is used as a boundary condition to solve eq. 2 . The initial condition is

$$
C=C_{0} \quad t=0, \quad x=0 \rightarrow l
$$

where $C_{0}$ is the initial water concentration in the hydrogel film (70 wt \% water throughout the film for all the cases considered here) and $l$ is the initial film thickness. In what follows, we examine two cases (denoted here as Model 1 and Model 2) for which eq. 2 has an analytical solution. We then solve eq. 2 numerically (Model 3) so that we relax assumptions involved in Models 1 and 2.

\section{Model 1: Semi-infinite Medium}

The drying process is assumed here as onedimensional diffusion (constant $D$ ) through a semi-infinite medium. An analytical solution (eq. 5 ) for the water concentration as a function of $x$ and $t$ can be obtained by solving eq. 2 for the

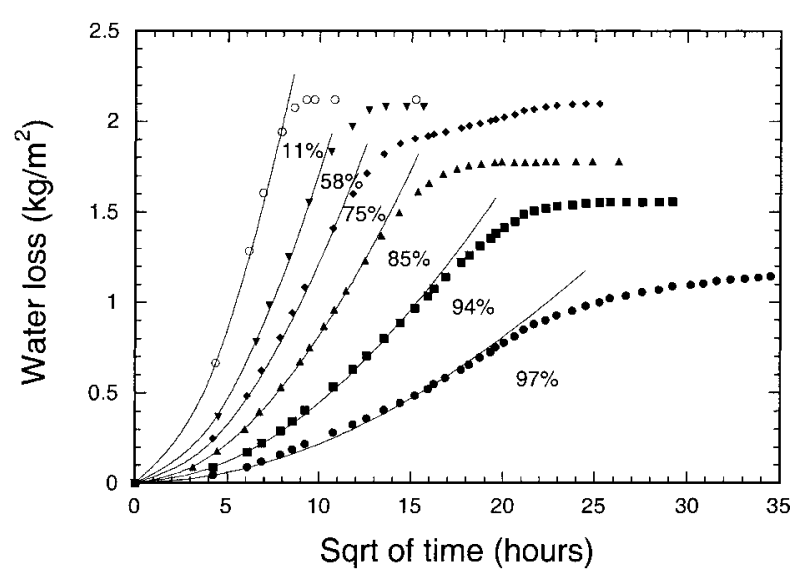

Figure 4. Water loss per unit area versus square root (Sqrt) of drying time at different $\mathrm{RH}$ values. The solid lines are the results from fitting the data with the water diffusion Model 1 (semi-infinite medium, constant diffusion coefficient). The $\mathrm{RH}$ values are indicated next to each data set. $\bigcirc 11 \% \mathrm{RH} ; \nabla 58 \% \mathrm{RH} ; \bullet 75 \% \mathrm{RH}$; $85 \% \mathrm{RH} ; \mathbf{9} \% \mathrm{RH} ; 97 \% \mathrm{RH}$.

$$
M(t)=\left(\frac{C_{\infty}-C_{0}}{p}\right)\left\{\exp \left(p^{2} D t\right) \operatorname{erfc}(p \sqrt{D t})-1+\frac{2}{\sqrt{\pi}} p \sqrt{D t}\right\}
$$

boundary and initial conditions shown in eqs. 3 and 4 , respectively. ${ }^{79}$ In the case of semi-infinite medium, $x$ ranges from 0 (film surface) to $\infty$ in eq. 4. At $x=\infty$, the water concentration equals the initial water concentration at all times.

$$
\begin{aligned}
\frac{C-C_{0}}{C_{\infty}-C_{0}}= & \operatorname{erfc} \frac{x}{2 \sqrt{D t}} \\
& -\exp \left(p x+p^{2} D t\right) \operatorname{erfc}\left(\frac{x}{2 \sqrt{D t}}+p \sqrt{D t}\right)
\end{aligned}
$$

where $p=\alpha / D$. The rate of the total amount of water $[M(t)]$ that has crossed a unit surface area by time $t$ is given by

$$
\frac{d M(t)}{d t}=-\left(D \frac{\partial C}{\partial x}\right)_{x=0}=\alpha\left(C_{\infty}-C_{s}\right)
$$

Substituting eq. 5 into eq. 6 and integrating from $t=0$ to $t$, we can obtain the total quantity of water that has crossed the unit area of the surface $^{79}$ :

\section{Values of Parameters Obtained by Fitting to Model 1}

The experimental water weight loss data have been fitted by eq. 7 (Fig. 4). Model 1 fitted very well the experimental results in stage I of the drying process using a water diffusion coefficient value of $D=5 \times 10^{-10} \mathrm{~m}^{2} / \mathrm{s}$ and proportionality constant values $(\alpha)$ that depend on the air $\mathrm{RH}$ (see Table 3a). However, there is a large deviation between the fitted values and experimental results in stage II. We will discuss the possible reasons for this large deviation in the next section. It may be reasonable to think that the point where the Model 1 starts to fail to fit the experimental data is the point where the concentration of water at the bottom of the film starts to change (i.e., the assumption of semi-infinite film thickness does not hold). However, this is not the case. For example, at $11 \% \mathrm{RH}$, the time scale when the water concentration at the bottom of the film $(l=3 \mathrm{~mm})$ starts to change (to become $90 \%$ of the initial concentration) is about $17 \mathrm{~min}$, 
Table 3a. Proportionality Constant $(\alpha)$ in the Film-Air Interface Boundary Condition in Poloxamer 407 Gels ( $l=3 \mathrm{~mm}$ Initially)

\begin{tabular}{lcccccc}
\hline & \multicolumn{5}{c}{$R H, \%$} \\
\cline { 2 - 7 } & 11 & 58 & 75 & 85 & 94 & 97 \\
\hline$\alpha^{\mathrm{I}}, \mathrm{m} / \mathrm{s}$ & $15.5 \times 10^{-9}$ & $8 \times 10^{-9}$ & $5.5 \times 10^{-9}$ & $5.8 \times 10^{-9}$ & $4.0 \times 10^{-9}$ & $3.3 \times 10^{-9}$ \\
$\alpha^{\mathrm{II}}, \mathrm{m} / \mathrm{s}$ & $15.0 \times 10^{-9}$ & $8 \times 10^{-9}$ & $5.5 \times 10^{-9}$ & $5.0 \times 10^{-9}$ & $4.0 \times 10^{-9}$ & $3.3 \times 10^{-9}$ \\
$\alpha^{\mathrm{III}}, \mathrm{m} / \mathrm{s}$ & $16.0 \times 10^{-9}$ & $8 \times 10^{-9}$ & $5.3 \times 10^{-9}$ & $5.9 \times 10^{-9}$ & $4.1 \times 10^{-9}$ & $3.6 \times 10^{-9}$ \\
\hline
\end{tabular}

which is much smaller than the time when the Model 1 starts to fail to fit the experimental data, about $63 \mathrm{~h}$.

\section{Water Diffusion Coefficient}

The diffusion coefficient of water in Poloxamer hydrogels has been shown to depend on the Poloxamer PEO/PPO composition and molecular weight, and on the Poloxamer concentration and temperature. ${ }^{80,81}$ In particular, the diffusion coefficient of water in Pluronic P105 $\left[(\mathrm{EO})_{37}(\mathrm{PO})_{50}(\mathrm{EO})_{37}\right]$ hydrogels was found to decrease exponentially from $3 \times 10^{-10}$ to $5 \times 10^{-12} \mathrm{~m}^{2} / \mathrm{s}$ with an increase of Poloxamer concentration in the range of $25 \sim 90 \mathrm{wt} \% .^{81} \mathrm{In}$ this study, a constant diffusion coefficient was adequate to fit well stage I of the drying process for various air $\mathrm{RH}$ conditions and for different film thicknesses (see section Effect of Film Thickness), which suggests that the contribution to the diffusion coefficient from the gel structure is not pronounced in stage $\mathrm{I}$. The value of the diffusion coefficient $(D), 5.0 \times 10^{-10} \mathrm{~m}^{2} / \mathrm{s}$, obtained from fitting with Model 1 is comparable to the diffusion coefficient in the micellar cubic phase in the Pluronic P105-water system reported by Yang. ${ }^{81}$ The self-diffusion coefficient of water in pure water is $2.23 \times 10^{-9} \mathrm{~m}^{2} / \mathrm{s}$ at $25^{\circ} \mathrm{C}$. $^{82}$ The value we obtained from Model 1 is one order of magnitude lower than this value, which is reasonable given that the PPO part of the volume is inaccessible to water. The water self-diffusion coefficient in Poloxamer 407 aqueous solutions was studied by NMR and it was found that the water selfdiffusion coefficient decreased monotonically with increasing Poloxamer concentration in the range $1 \sim 40 \mathrm{wt} \% .^{74}$ The water self-diffusion was half of the self-diffusion coefficient of neat water at $27^{\circ} \mathrm{C}$, about $1.1 \times 10^{-9} \mathrm{~m}^{2} / \mathrm{s}$, when the Poloxamer concentration was $40 \mathrm{wt} \%{ }^{74}$ The value obtained from our fitting with Model 1 is about half of this literature value, which is reasonable because our fittings covered a range of higher Poloxamer concentrations. The water diffusion coefficient in Poloxamer 407 hydrogel was reported as $4.3 \times 10^{-9} \mathrm{~m}^{2} / \mathrm{s}$ at $24 \mathrm{wt} \%$ Poloxamer and $2.3 \times 10^{-9} \mathrm{~m}^{2} / \mathrm{s}$ at 30 wt $\%$ Poloxamer at $37^{\circ} \mathrm{C} .^{50,83}$ This water diffusion coefficient was obtained by measuring the water transport in a simple syringe system and by fitting the experimental results with Fickian models and appropriate boundary conditions. ${ }^{50,83}$ These values are very close to the self-diffusion coefficient of water.

Water diffusion coefficient values in systems of medical significance, for example, contact lens hydrogels, bicontinuous cubic phase, and phospholipid membrane, have been reported in the literature ${ }^{84-86}$ and are summarized in Table 4. The water self-diffusion coefficient (measured by NMR) for eight commercial contact lens hydrogels was found in the range $4.7 \sim 14.7 \times 10^{-10} \mathrm{~m}^{2} / \mathrm{s} .{ }^{86}$ Water diffusion in the lamellar phase of egg phosphatidylcholine-water system was studied by the pulsed field gradient-spin echo $\mathrm{H}-1 \mathrm{NMR},{ }^{84}$ and the water diffusion coefficients in the direction parallel to the lipid bilayer ranged from $1.2 \times 10^{-10}$ (4.9 moles water/lipid) to $4.0 \times 10^{-10} \mathrm{~m}^{2} / \mathrm{s}(18.6$ moles water/lipid) at $25^{\circ} \mathrm{C}$, very similar to the values obtained in the Pluronic P105-water system. ${ }^{81} \mathrm{~A}$ water diffusion coefficient of $1.2 \times 10^{-10} \mathrm{~m}^{2} / \mathrm{s}$ at $23^{\circ} \mathrm{C}$ was reported in a bicontinuous cubic phase formed by monoacylglycerol and diacylglycerol in about $25 \mathrm{wt} \% \mathrm{H}_{2} \mathrm{O} .^{85}$ This value is five times lower than the value obtained from our fitting but in the same order of magnitude with the diffusion coefficient in the Pluronic P105 hexagonal phase. ${ }^{81}$

\section{Proportionality Constant $\alpha$}

The proportionality constant was determined using the above model at various air $\mathrm{RH}$ conditions. The proportionality constant ranges from 
3.3 to $15.5 \times 10^{-9} \mathrm{~m} / \mathrm{s}$ and is a linear function of the $\mathrm{RH}$ at a given film thickness (see Table 3a). As mentioned earlier, the drying in stage $I$ is controlled (limited) by the outside air conditions and not by the diffusion in the gel. The linear correlation between the proportionality constant and the $\mathrm{RH}$ validates this postulation. The proportionality constant values reported here are very similar to those obtained from the evaporation rate of pure water under the same drying conditions (conducted as a control experiment in our study).

\section{Model 1 Assumptions}

In modeling the drying of the block copolymer hydrogels as described above, the following assumptions have been made: (1) The water concentration is uniform throughout the hydrogel film at time $=0$. This has indeed been the case in our experiments. (2) The density of block copolymer aqueous solution/gel is assumed to be $1 \mathrm{~g} / \mathrm{cm}^{3}$ (constant). (3) There is no temperature change in the gel film during the drying process: isothermal process. (4) Water diffuses only along the direction perpendicular to the surface of the hydrogel film: one-dimensional diffusion. This is a reasonable assumption because the ratio of the diameter of the small container to the film thickness is generally very large; for example, when the initial film thickness is $3 \mathrm{~mm}$, the ratio is about 12 . (5) The surface evaporation rate is linear with respect to the difference between the water concentration on the surface and the concentration at equilibrium with the water vapor pressure in the air (eq. 3). This is a common description for evaporation rate at a surface. ${ }^{18,69,76,79,87}$ (6) The hydrogel film is assumed as semi-infinite in the water diffusion direction. At the early stage of drying, this is a reasonable assumption because the water concentration at the bottom of the container will be the same as the initial concentration. We relax this assumption in Model 2 (finite, constant film thickness) and Model 3 (variable film thickness). (7) The water diffusion coefficient in the hydrogel film is constant. Although the water diffusion coefficient is a function of block copolymer concentration, ${ }^{81}$ the value $\left(5.0 \times 10^{-10}\right.$ $\mathrm{m}^{2} / \mathrm{s}$ ) that we used in Model 1 fitting is in the same order as the water diffusion coefficient obtained in the micellar cubic and hexagonal phases of Pluronic P105 hydrogel; these structures are also observed during stage I of drying. We relax this assumption and use variable diffusion coefficient in the numerical fittings of Model 3 presented later.

\section{Model 2: Finite (Constant) Film Thickness}

The governing diffusion equation for a film of finite (constant) thickness is still eq. 2. The boundary condition at the bottom of the hydrogel film $(x=0)$ is given by eq. 8 shown below.

$$
D \frac{\partial C}{\partial x}=0
$$

The boundary condition at the film surface $(x=l)$ is eq. 3 , but with opposite sign (because of $x=0$ being now at the bottom of the film). The analytical solution of eq. 2 with constant $D$, the above boundary condition and eq. 4 as initial condition is as follows ${ }^{79}$ :

$$
\frac{C-C_{0}}{C_{\infty}-C_{0}}=1-\sum_{n=1}^{\infty} \frac{2 L \cos \left(\beta_{n} x / l\right) \exp \left(-\beta_{n}^{2} D t / l^{2}\right)}{\left(\beta_{n}^{2}+L^{2}+L\right) \cos \beta_{n}}
$$

$\beta_{n} \mathrm{~s}$ are the positive roots of eq. 10 .

$$
\beta \tan \beta=L \text { and } L=l \alpha / D
$$

In this model, the total amount of water that has crossed a unit film surface area at time $t, M(t)$, is expressed by the following equation ${ }^{79}$ :

$$
\frac{M(t)}{M_{\infty}}=1-\sum_{n=1}^{\infty} \frac{2 L^{2} \exp \left(-\beta_{n}^{2} D t / l^{2}\right)}{\beta_{n}^{2}\left(\beta_{n}^{2}+L^{2}+L\right)}
$$

where $M_{\infty}$ is the total amount of water that has crossed a unit film surface area at infinite time.

We used eq. 11 to fit the experimental results of drying of the hydrogel film as shown in Figure 5. Model 2 captures the experimentally observed trend better than Model 1 over the whole concentration range; however, Model 2 does not have the accuracy of Model 1 in stage I of the drying process. In the new fits, the same water diffusion coefficient, $D=5.0 \times 10^{-10} \mathrm{~m}^{2} / \mathrm{s}$, was used as in Model 1 . The proportionality constants $\alpha$ used in the Model 2 fittings are identical or very close to the values obtained in the Model 1 fits (see Table 3a). The water concentration distribution in the hydrogel film at any time $t$ is described in the context of Model 2 by eq. 9 . The water concentration profiles thus obtained are rather flat at all times (data not shown here).

When using Model 2 for fitting the experimental data, the hydrogel film was assumed to be of fixed thickness. However, the film thickness decreases 


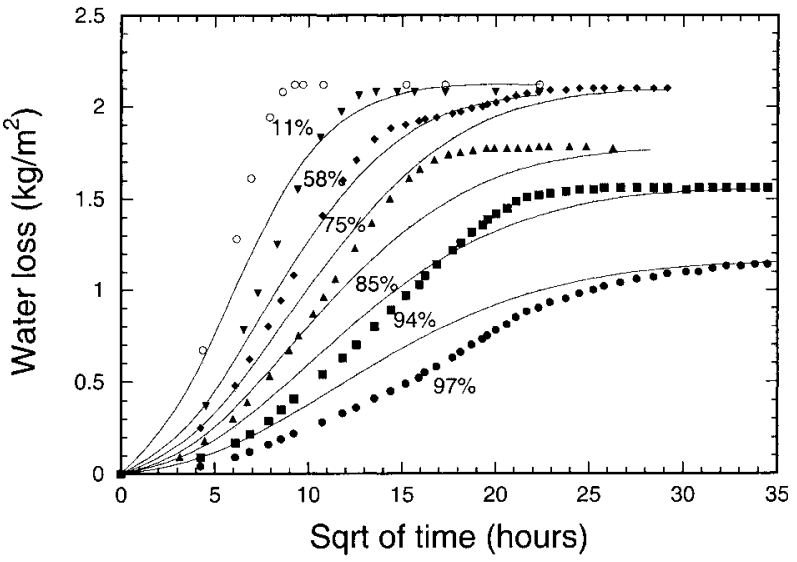

Figure 5. Water loss per unit area versus square root (Sqrt) of drying time at different $\mathrm{RH}$ values. The solid lines are the results from fitting the data with water diffusion Model 2 (finite and constant film thickness, constant diffusion coefficient). The symbols indicate the same RH conditions as in Figure 4.

during the drying process. Also, the assumption of constant diffusion coefficient which is not severe in the Model 1 fitting of stage I, becomes significant in Model 2 as it covers the whole block copolymer concentration range. Numerical modeling of this drying process for the case of variable film thickness and variable diffusion coefficient is presented in the Model 3 section. The analytical solutions (Model 1 and 2) used here are still useful because they provide an easy estimation of drying parameters.

\section{Model 3: Variable Film Thickness and Diffusion Coefficient}

In the case of variable film thickness (function of water content in the film), the boundary condition at the film-air interface is obtained by a jump mass balance, ${ }^{52,53,56-58,60}$ where the term $C[d h(t) /$ $d t$ ] accounts for water flux due to the moving boundary (this term could be neglected under the quasi-steady-state approximation)

$$
-D \frac{\partial C}{\partial x}-C \frac{d h(t)}{d t}=\alpha\left(C_{s}-C_{\infty}\right), x=h(t)
$$

The film thickness is obtained by polymer mass balance in the gel film.

$$
h(t)=\frac{l\left(1-w_{0, \mathrm{H}_{2} \mathrm{O}}\right)}{1-\bar{w}_{\mathrm{H}_{2} \mathrm{O}}(t)}
$$

where $w_{0, \mathrm{H}_{2} \mathrm{O}}$ is the initial water weight fraction; $\bar{w}_{\mathrm{H}_{2} \mathrm{O}}(t)$ is the average water weight fraction in the film at time $t$.

The total quantity of water that has crossed a unit area of the film surface by time $t, M(t)$, is

$$
\begin{aligned}
M(t) & =l C_{0, \mathrm{H}_{2} \mathrm{O}}-h(t) \bar{C}_{\mathrm{H}_{2} \mathrm{O}}(t) \\
& =l C_{0, \mathrm{H}_{2} \mathrm{O}}-h(t) \int_{0}^{h(t)} C(x, t) d x
\end{aligned}
$$

The water diffusion coefficient in the gel is assumed to be an exponential function of water concentration $^{87,88}$

$$
D=D_{0} e^{-k / C}
$$

where $D_{0}$ is a pre-exponential factor (it has units of diffusion coefficient), and $k$ is a constant (the same units as $C$ ).

The governing equation (eq. 2), together with the initial condition (eq. 4) and boundary conditions (eqs. 8 and 12), can be solved numerically. The fitting results shown in Figure 6a indicate great improvement over Models 1 and 2. The numerical results also capture the film thickness evolution and the results are shown in Figure 6b. When solving eq. 2 numerically, $D=1.0 \times 10^{-10}$ $\exp \left(-0.1 / \mathrm{C}^{\prime}\right)$ was used and $\alpha$ values that are listed in Table $3 \mathrm{a}\left(\mathrm{C}^{\prime}=\mathrm{C} / \mathrm{C}_{0}\right.$, dimensionless concentration). These values are exactly the same or very close to the values obtained from Models 1 and 2 fittings. It should be noted that the $D_{0}$ and $k$ values are not as sensitive in the fittings as the $\alpha$ values. This further validates that the film-air interface has an important role in the drying process. The water distributions in the film, obtained from the numerical solution, at different times during drying at 58\% RH are shown in Figure 7. The film shrank significantly at the beginning of the drying process. The water concentration profiles are rather flat.

\section{Effect of Film Thickness}

Figure 8a and $\mathrm{b}$ show the effect of film thickness on the water weight loss during the drying course. The two-stage drying mechanism is maintained when the film thickness is changed; however, the drying time is greatly shortened when a lower film thickness is used. For example, at $58 \% \mathrm{RH}$ when the film thickness is reduced from 5 to 1 $\mathrm{mm}$, the drying time needed for achieving $>99.5 \%$ of total water loss is reduced from 360 to $63 \mathrm{~h}$.

When the models used to fit the experimental results represent reality well, the water diffusion coefficient and proportionality constants should be 

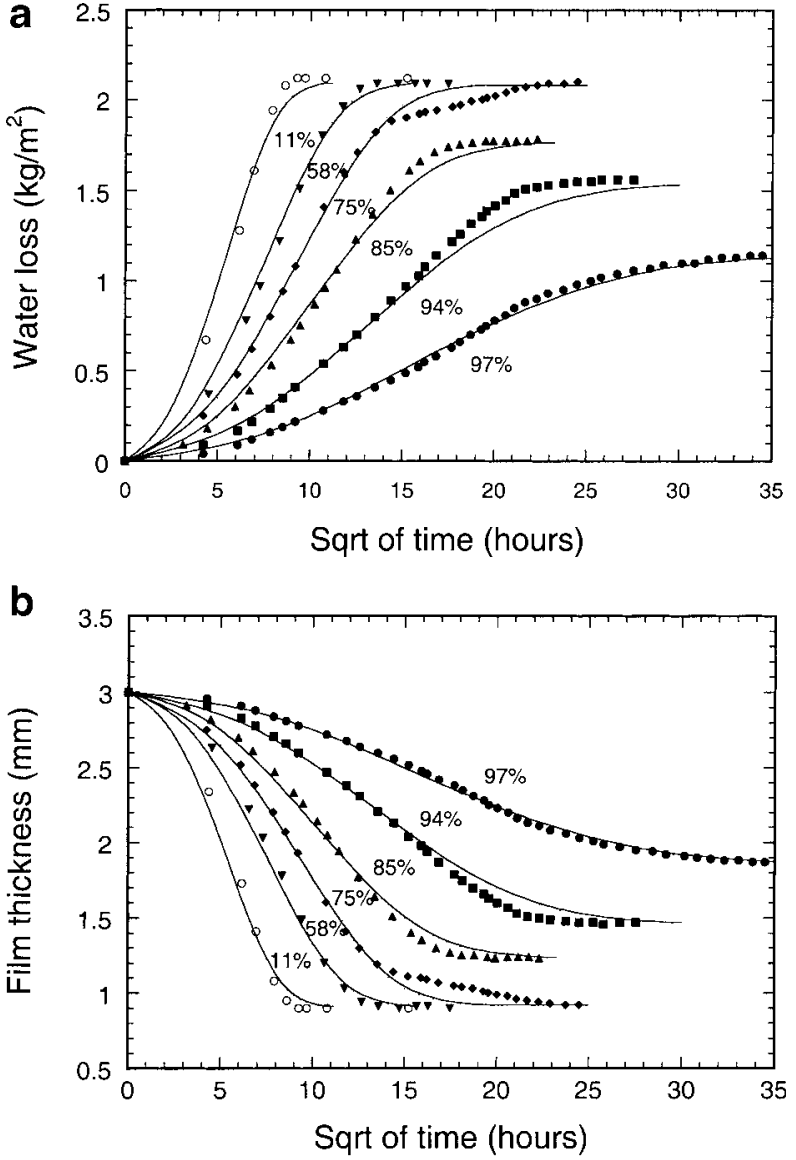

Figure 6. (a) Water loss per unit area versus square root (Sqrt) of drying time at different $\mathrm{RH}$ values. (b) Change of film thickness in the drying of Poloxamer 407 at different $\mathrm{RH}$ values. The solid lines are the results from fitting the data with water diffusion Model 3 (variable film thickness and diffusion coefficient a function of water concentration). The symbols indicate the same RH conditions as in Figure 4.

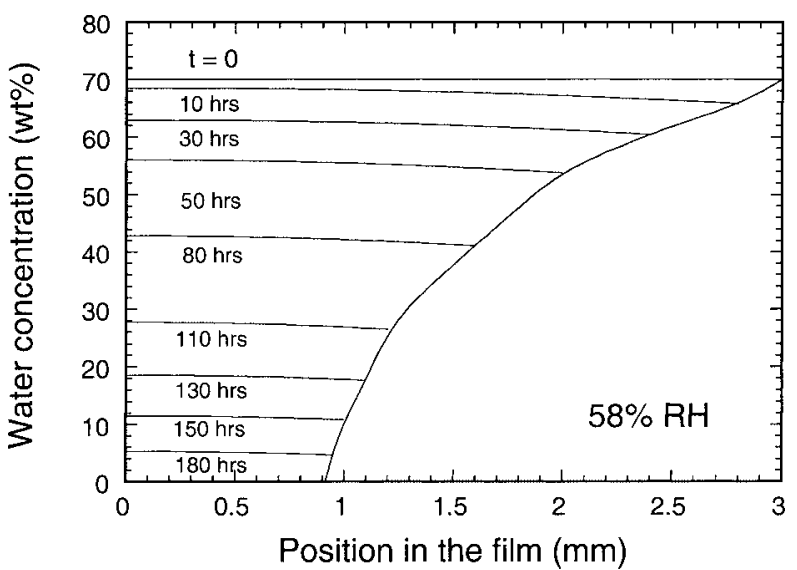

Figure 7. Water distribution at different times during the drying of Poloxamer 407 hydrogel film at 58\% $\mathrm{RH}$, predicted from Model 3.
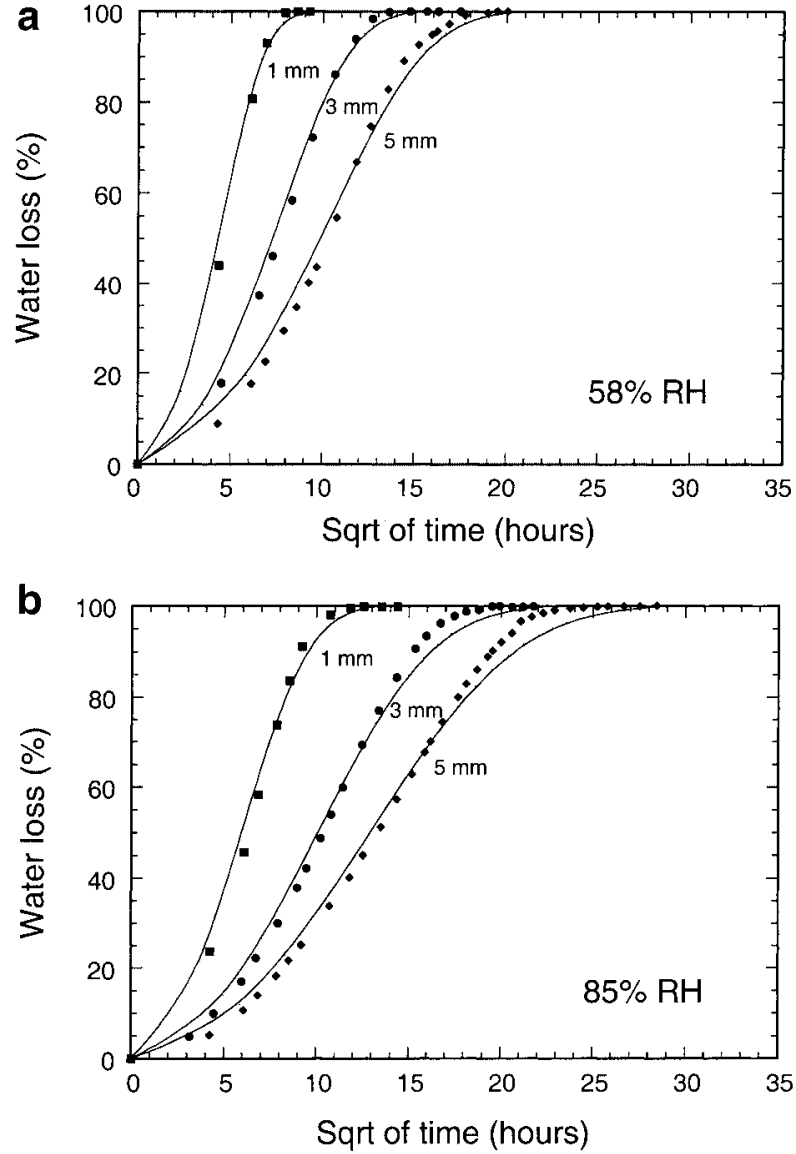

Figure 8. Film thickness effect on the drying kinetics of Poloxamer 407 hydrogel film at two different relative humidities: (a) $58 \% \mathrm{RH}$, and (b) $85 \% \mathrm{RH}$. The lines are the fits using Model 3. Film thickness: $1 \mathrm{~mm} ; 3 \mathrm{~mm}$; $\diamond 5 \mathrm{~mm}$.

the same even if the film thickness is changed. The three models have been used to fit the experimental data at different film thickness and the results are listed in Table $3 \mathrm{~b}$. The fitting results from Model 3 are shown in Figure 8a and b. All three models fit adequately the data at different film thicknesses with the same diffusion coefficient and almost the same proportionality constant (see Table 3b). This means that the thickness of films has no effect or very small effect on the proportionality constant. When Model 1 is used for fitting the data for $85 \% \mathrm{RH}, \alpha$ increases from $4.8 \times 10^{-9}$ to $6.0 \times 10^{-9} \mathrm{~m} / \mathrm{s}$ (25\% change) when the film thickness increases from 1 to $5 \mathrm{~mm}$. However, this change is relatively small compared with the fivefold change in $\alpha$ when the $\mathrm{RH}$ varies in the range of $11-97 \% \mathrm{RH}$ (Table $3 \mathrm{a}$ ). So, our results and models are consistent, and we can use the water diffusion coefficient $D$ and proportionality constant $\alpha$ obtained from fitting our experimental 
Table 3b. Proportionality Constant $(\alpha)$ in the Film-Air Interface Boundary Condition in Poloxamer 407 Gels at Various Initial Film Thicknesses

\begin{tabular}{|c|c|c|c|c|c|c|}
\hline & \multicolumn{6}{|c|}{$R H, \%$} \\
\hline & \multicolumn{3}{|c|}{58} & \multicolumn{3}{|c|}{85} \\
\hline & $1 \mathrm{~mm}$ & $3 \mathrm{~mm}$ & $5 \mathrm{~mm}$ & $1 \mathrm{~mm}$ & $3 \mathrm{~mm}$ & $5 \mathrm{~mm}$ \\
\hline$\alpha^{\mathrm{I}}, \mathrm{m} / \mathrm{s}$ & $6.8 \times 10^{-9}$ & $8.0 \times 10^{-9}$ & $7.8 \times 10^{-9}$ & $4.8 \times 10^{-9}$ & $5.8 \times 10^{-9}$ & $6.0 \times 10^{-9}$ \\
\hline$\alpha^{\mathrm{II}}, \mathrm{m} / \mathrm{s}$ & $8.0 \times 10^{-9}$ & $8.0 \times 10^{-9}$ & $8.0 \times 10^{-9}$ & $5.0 \times 10^{-9}$ & $5.0 \times 10^{-9}$ & $5.0 \times 10^{-9}$ \\
\hline$\alpha^{\mathrm{III}}, \mathrm{m} / \mathrm{s}$ & $7.5 \times 10^{-9}$ & $8.0 \times 10^{-9}$ & $7.3 \times 10^{-9}$ & $5.5 \times 10^{-9}$ & $5.0 \times 10^{-9}$ & $6.0 \times 10^{-9}$ \\
\hline
\end{tabular}

data to predict drying kinetics at different film thicknesses.

\section{Drying of PEO Homopolymers}

The drying of poly(ethylene glycol) homopolymer (PEG4000 and PEG20000) aqueous solutions at two different $\mathrm{RHs}(58 \%$ and $85 \%$ ) was investigated in this study as a control experiment for the drying of Poloxamer hydrogels. Poloxamer is an amphiphilic molecule and forms ordered self-assembled structures, whereas PEG does not self-assemble. The PEO molecular weight of Poloxamer 407 is about 9000 , between the molecular weights of PEG4000 and PEG20000. The equilibrium concentrations of PEG and the final forms after drying are shown in Table 5. Also shown in Table 5 are the hydration levels $\left(\mathrm{H}_{2} \mathrm{O} /\right.$ EO molar ratio) at equilibrium. The equilibrium states of PEG20000 at both air RH conditions examined are solid, whereas the equilibrium state of PEG4000 is solid at 58\% RH and solution at $85 \% \mathrm{RH}$. This is because PEG20000 has a higher molecular weight than PEG4000 and is easier to crystallize. In the early stage of the drying of PEG4000 and PEG20000 solutions (Fig. 9a and $9 \mathrm{~b}$ ), the water weight loss was a linear function of drying time, similarly to stage I of Poloxamer 407 hydrogel. This suggests that at stage I, the polymer concentration is important but not the polymer structure. In stage II of the drying of PEG4000 solution at 58\% RH and of PEG20000 at both 58 and $85 \%$ relative humidities, a region where the water loss is a linear function of square root of time has been observed. This region is similar to what has been observed in the drying of Poloxamer 407 hydrogel at $75 \% \mathrm{RH}$. The region commenced when the PEG changed from a transparent solution to an opaque semicrystalline form, at concentrations of about $70 \mathrm{wt} \%$ for PEG4000 and 64 wt \% for PEG20000. Model 3 can capture very well the stage I data for all PEG samples and the stage II data for PEG4000 at $85 \% \mathrm{RH}$ (using the $\alpha$ and $D$ values reported in Table 3c), but not the region in stage II drying discussed above (as seen in Fig. 9). This suggests that the diffusion mechanism operating at these specific conditions may be different than that described by Model 3.

As mentioned earlier, such a region is very clear in the drying of Poloxamer 407 hydrogel at $75 \%$ $\mathrm{RH}$, but less visible at 58 and $11 \%$ RHs. For example, the duration of this region for Poloxamer 407 at $75 \% \mathrm{RH}$ is about $260 \mathrm{~h}$, but is only $11 \mathrm{~h}$ at $11 \% \mathrm{RH}$. The crystallization time for neat PEO (viscosity-average molecular weight $1.44 \times 10^{5}$ )

Table 3c. Proportionality Constant $(\alpha)$ in the Film-Air Interface Boundary Condition in PEG4000 and PEG20000 Aqueous Solutions ( $l=3 \mathrm{~mm}$ Initially)

\begin{tabular}{|c|c|c|c|c|}
\hline & \multicolumn{2}{|c|}{ PEG4000 } & \multicolumn{2}{|c|}{ PEG20000 } \\
\hline & $58 \% R H$ & $85 \% R H$ & $58 \% R H$ & $85 \% R H$ \\
\hline$\alpha^{\mathrm{I}}, \mathrm{m} / \mathrm{s}$ & $8.0 \times 10^{-9}$ & $6.0 \times 10^{-9}$ & $7.0 \times 10^{-9}$ & $3.4 \times 10^{-9}$ \\
\hline$\alpha^{\mathrm{II}}, \mathrm{m} / \mathrm{s}$ & $8.0 \times 10^{-9}$ & $6.0 \times 10^{-9}$ & $7.0 \times 10^{-9}$ & $3.4 \times 10^{-9}$ \\
\hline$\alpha^{\mathrm{III}}, \mathrm{m} / \mathrm{s}$ & $7.5 \times 10^{-9}$ & $6.2 \times 10^{-9}$ & $7.0 \times 10^{-9}$ & $3.5 \times 10^{-9}$ \\
\hline
\end{tabular}

The proportionality constant $\alpha^{\mathrm{I}}$ values are obtained from the Model 1 fits. $D=5.0 \times 10^{-10} \mathrm{~m}^{2} / \mathrm{s}$.

The $\alpha^{\mathrm{II}}$ values are obtained from the Model 2 fits. $D=5.0 \times 10^{-10} \mathrm{~m}^{2} / \mathrm{s}$.

The $\alpha^{\mathrm{III}}$ values are obtained from the Model 3 fits. $D=1.0 \times 10^{-10} \exp \left(-0.1 / C^{\prime}\right) \mathrm{m}^{2} / \mathrm{s}$. 
Table 4. Diffusion Coefficient of Water in Different Systems of Biomedical Significance

\begin{tabular}{|c|c|c|c|c|c|}
\hline & \multicolumn{5}{|c|}{ System } \\
\hline & Pure Water ${ }^{a}$ & $\begin{array}{l}\text { Contact Lens } \\
\text { Hydrogels }^{b}\end{array}$ & $\begin{array}{l}\text { Poloxamer } \\
\text { P407 gel }\end{array}$ & $\begin{array}{l}\text { Bicontinuous } \\
\text { Cubic Phase }^{d}\end{array}$ & $\begin{array}{l}\text { Phospholipid } \\
\text { Membrane }^{e}\end{array}$ \\
\hline$D_{W}, \mathrm{~m}^{2} / \mathrm{s}$ & $2.23 \times 10^{-9}$ & $4.7-14.7 \times 10^{-10}$ & $5.0 \times 10^{-10}$ & $1.2 \times 10^{-10}$ & $1.2-4.0 \times 10^{-10}$ \\
\hline $\begin{array}{l}{ }^{a} \text { Water } \\
{ }^{b} \text { Eight c } \\
{ }^{c} \text { This str } \\
{ }^{d} \text { Monoas } \\
{ }^{e} \text { Lamell }\end{array}$ & $\begin{array}{l}\text { fusion coefficien } \\
\text { rcial contact len } \\
\text { erol and diacylg } \\
\text { se of egg phosph }\end{array}$ & $\begin{array}{l}\text { C. }^{82} \\
\text { rogels. } \\
\\
\text { ol, } 23^{\circ} \mathrm{C}^{85} \\
\text { lcholine-water. }^{84}\end{array}$ & & & \\
\hline
\end{tabular}

from the amorphous state (about 10-20\% crystallinity) to about $70 \%$ crystallinity was reported from about several minutes at $45^{\circ} \mathrm{C}$ to about $3 \mathrm{~h}$ at $52^{\circ} \mathrm{C} .{ }^{89,90}$ Although the PEO crystallization time reported in the literature may not be applicable in our system because the systems examined and the temperature are different, it indeed indicates that the crystallization time of $\mathrm{PEO}$ is shorter than the drying time even at the very low $\mathrm{RH}$ case. The less visible linear water loss versus square root of time region at low $\mathrm{RH}$ is due to the fewer data points collected because of faster drying.

\section{CONCLUSIONS}

The drying of films formed by Poloxamer 407 hydrogels was investigated at various air $\mathrm{RH}$ conditions covering the range from 11 to $97 \%$. To the best of our knowledge, this is the first study for the drying of films formed by block copolymer or surfactant hydrogels that are exposed to known water vapor pressures. Parameters affecting the drying process, such as the air $\mathrm{RH}$ and film thickness, have been investigated and are reported here.

Two regimes are observed for the drying process, constant drying rate (stage I) and falling drying rate (stage II). The amount of water lost increases linearly with the drying time during stage I. After this linear region, a nonlinear behavior is observed. At conditions when the equilibrium state was semicrystalline, a region where the water loss was a linear function of square root of time was evident in stage II. The drying rate in stage I increases linearly with decreasing RH. Deceasing the film thickness greatly shortens the drying time, but the same drying mechanism is maintained. Two-stage drying was also observed in PEO homopolymer aqueous solutions. The results indicate that selfassembled structures present in Poloxamer 407 hydrogel are not important in the stage I drying, but the semicrystalline polymer structures formed by Poloxamer 407 and PEG at low water contents affect significantly the stage II drying as attested by observed changes in the slope of water loss versus time data.

Three models (of increasing complexity) for the diffusion of water in the film are used to fit the experimental results. Model 1 assumes semiinfinite medium and it fits the data very well in stage I of the drying process. A constant value of water diffusion coefficient $D=5.0 \times 10^{-10} \mathrm{~m}^{2} / \mathrm{s}$ is appropriate for fitting all the air $\mathrm{RH}$ conditions. The effect of the air $\mathrm{RH}$ conditions is described by a proportionality constant, $\alpha$, used in the boundary condition. The proportionality constant is a linear function of the air $\mathrm{RH}$, but is independent of the film thickness. Model 2 considers a finite

Table 5. Equilibrium Concentration, Form, and Hydration Level of PEG4000 and PEG20000 at 58\% and $85 \%$ Relative Humidities

\begin{tabular}{|c|c|c|c|c|c|c|}
\hline \multirow[b]{2}{*}{$R H, \%$} & \multicolumn{3}{|c|}{ PEG4000 } & \multicolumn{3}{|c|}{ PEG20000 } \\
\hline & $\begin{array}{l}\text { Equilibrium } \\
\text { Concentration }\end{array}$ & Final Form & $\begin{array}{c}\mathrm{H}_{2} \mathrm{O} / \mathrm{EO} \\
\text { Molar Ratio }\end{array}$ & $\begin{array}{l}\text { Equilibrium } \\
\text { Concentration }\end{array}$ & Final Form & $\begin{array}{c}\mathrm{H}_{2} \mathrm{O} / \mathrm{EO} \\
\text { Molar Ratio }\end{array}$ \\
\hline 58 & $98.60 \mathrm{wt} \%$ & Solid & 0.035 & 99.27 wt $\%$ & Solid & 0.018 \\
\hline 85 & 65.97 wt \% & Solution & 1.26 & 95.75 wt $\%$ & Solid & 0.11 \\
\hline
\end{tabular}



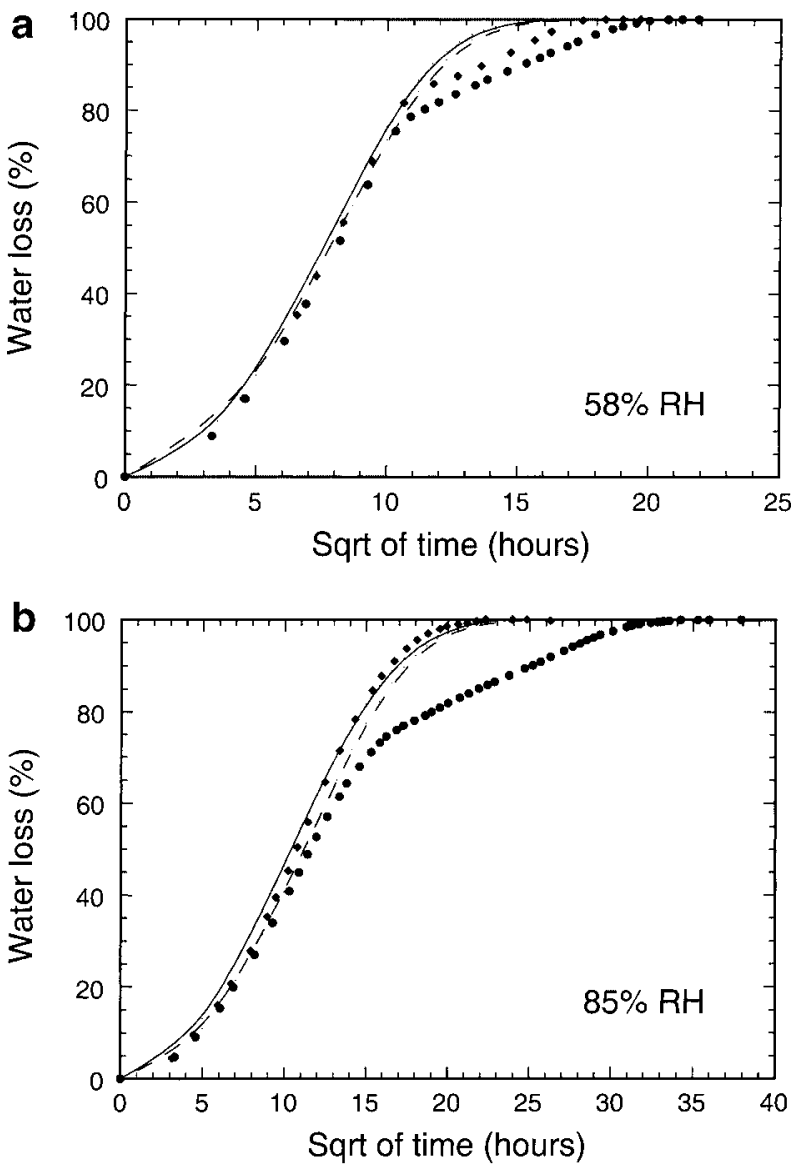

Figure 9. Water loss versus square root (Sqrt) of drying time for different PEO homopolymers. (a) Percentage of water loss versus square root of drying time at $58 \% \mathrm{RH}$. (b) Percentage of water loss versus square root of drying time at $85 \% \mathrm{RH}$. $\bullet$ Experimental results for PEG4000; experimental results for PEG20000; — results from Model 3 fitting for PEG4000; - - - - results from Model 3 fitting for PEG20000.

(constant) film thickness and captures the trend observed in the experiments over the whole drying period, but deviates from the experimental data at both low and high drying times. Model 2 uses the same $D$ and $\alpha$ values as in Model 1 . The analytical solutions available for Models 1 and 2 facilitate the easy utilization of the data presented in this article in practical applications. Numerical solutions for water diffusion under conditions of decreasing film thickness and variable diffusion coefficient are presented in Model 3. The fit of the data to the different models shows that the drying rate is more sensitive to the boundary condition at the film-air interface than to the diffusion in the film. It is notable that the $\alpha$ values obtained from the fits of the Poloxamer drying rate are comparable to those obtained from drying of water film under the same experimental conditions.

\section{ACKNOWLEDGMENTS}

Financial support to P.A. from the National Science Foundation (CTS-9875848/CAREER) is greatly appreciated.

\section{REFERENCES}

1. Rowe RC. 1985. Film-coating: The ideal process for the production of modified-release oral dosage forms. Pharm Int 6:14-17.

2. Bodmeier R, Paeratakul O. 1989. Evaluation of drug-containing polymer films prepared from aqueous latexes. Pharm Res 6:725-730.

3. Bodmeier R, Paeratakul O. 1994. Mechanical properties of dry and wet cellulosic and acrylic films prepared from aqueous colloidal polymer dispersions used in the coating of solid dosage forms. Pharm Res 11:882-888.

4. McGinity JW, editor. 1989. Aqueous polymeric coatings for pharmaceutical applications. New York: Marcel Dekker.

5. Porter SC. 1989. Controlled-release film coatings based on ethylcellulose. Drug Dev Ind Pharm 15: 1495-1521.

6. Narisawa S, Yoshino H, Hirakawa Y, Noda K. 1994. Porosity-controlled ethylcellulose film coating. II. Spontaneous porous film formation in the spraying process and its solute permeability. Int $J$ Pharm 104:95-106.

7. Paulsson M, Singh SK. 1999. Colloidal and thermal characteristics of concentrated dispersion of polymethacrylate-based latices for aqueous enteric coating. J Pharm Sci 88:406-411.

8. Schmidt C, Bodmeier R. 1999. Incorporation of polymeric nanoparticles into solid dosage forms. J Control Release 57:115-125.

9. Lippold BC, Pages RM. 2001. Film formation, reproducibility of production and curing with respect to release stability of functional coatings from aqueous polymer dispersions. Pharmazie 56:5-17.

10. Tarvainen M, Sutinen R, Peltonen S, Tiihonen P, Paronen P. 2002. Starch acetate: A novel filmforming polymer for pharmaceutical coatings. J Pharm Sci 91:282-289.

11. Smith JS, Peppas NA. 1991. Mathematical analysis of transport properties of polymer films for food packaging. VII. Moisture transport through a polymer film with subsequent adsorption and diffusion through food. J Appl Polym Sci 43:1219_ 1225 . 
12. Schmolka IR. 1972. Artificial skin. I. Preparation and properties of poloxamer 407 gels for the treatment of burns. J Biomed Mater Res 6:571-582.

13. Niemi L, Laine E. 1991. Effect of water content on the microstructure of an $\mathrm{O} / \mathrm{W} /$ cream. Int J Pharm 68:205-214.

14. Yang L, Alexandridis P. 2000. Physicochemical aspects of drug delivery and release from polymerbased colloids. Curr Opin Colloid Interface Sci 5: 132-143.

15. Peppas NA, Hansen PJ, Buri PA. 1984. A theory of molecular-diffusion in the intestinal mucus. Int $\mathrm{J}$ Pharm 20:107-118.

16. Larhed AW, Artursson P, Grasjo J, Bjork E. 1997. Diffusion of drugs in native and purified gastrointestinal mucus. J Pharm Sci 86:660-665.

17. Khanvilkar K, Donovan MD, Flanagan DR. 2001. Drug transfer through mucus. Adv Drug Deliver Rev 48:173-193.

18. Laghoueg-Derriche N, Vergnaud JM. 1991. Modeling the process of drying of dosage forms made of drug dispersed in a polymer. Int J Pharm 67:51-57.

19. Laghoueg-Derriche N, Vergnaud JM. 1991. Drying of dosage forms prepared by a humidity technique using a programmed temperature system. Int $\mathrm{J}$ Pharm 71:229-236.

20. Grandfils C, Flandroy P, Nihant N, Barbette S, Jerome R, Teyssie P, Thibaut A. 1992. Preparation of poly $(\mathrm{D}, \mathrm{L})$ lactide microspheres by emulsionsolvent evaporation, and their clinical applications as a convenient embolic material. J Biomed Mater Res 26:467-479.

21. Chidavaenzi OC, Buckton G, Koosha F. 2001. The effect of co-spray drying with polyethylene glycol 4000 on the crystallinity and physical form of lactose. Int J Pharm 216:43-49.

22. Travers DN. 1975. A comparison of solute migration in a test gradulation dried by fluidization and other methods. J Pharm Pharmacol 27:516-522.

23. Carstensen JT, Zoglio MA. 1982. Tray drying of pharmaceutical wet granulations. J Pharm Sci 71:35-39.

24. Sato T, Kanke MM, Schroeder HG, Deluca PP. 1988. Porous biodegradable microspheres for controlled drug delivery. I. Assessment of processing conditions and solvent removal technique. Pharm Res 5:21-30.

25. Chatrath M, Staniforth JM. 1990. The relative influence of dielectric and other drying techniques on the physico-mechanical properties of a pharmaceutical tablet excipient. Part I. Compaction characteristics. Drying Technol 8:1089-1109.

26. Bataille B, Ligarski K, Jacob M, Thomas C, Duru C. 1993. Study of the influence of spheronization and drying conditions on the physico-mechanical properties of neutral spheroids containing Avicel PH 101 and lactose. Drug Dev Ind Pharm 19:653-671.

27. Dyer AM, Khan KA, Aulton ME. 1994. Effect of the drying method on the mechanical and drug release properties of pellets prepared by extrusion-spheronization. Drug Dev Ind Pharm 20:3045-3068.

28. Mandal TK. 1995. Evaluation of microwave drying for pharmaceutical granulations. Drug Dev Ind Pharm 21:1683-1688.

29. Jeyanthi R, Mehta RC, Thanoo BC, Deluca PP. 1996. Effects of solvent removal technique on the matrix characteristics of polylactide/glycolide microspheres for peptide delivery. J Control Release 38:235-244.

30. Jeyanthi R, Mehta RC, Thanoo BC, Deluca PP. 1997. Effect of processing parameters on the properties of peptide-containing PLGA microsphere. J Microencapsul 14:163-174.

31. Li WI, Anderson KW, Mehta RC, Deluca PP. 1996 Prediction of solvent removal profiles and effect on properties for peptide-loaded PLGA microspheres prepared by solvent extraction/evaporation method. J Control Release 37:199-214.

32. Darcy P, Buckton G. 1997. The influence of heating/ drying on the crystallisation of amorphous lactose after structural collapse. Int J Pharm 158:157-164.

33. Habib YS, Shangraw RF. 1997. Effect of different drying techniques on the physico-mechanical properties of beads containing microcrystalline cellulose (MCC) produced by extrusion spheronization. Pharm Res 14:S14.

34. Berggren J, Alderborn G. 2001. Drying behaviour of two sets of microcrystalline cellulose pellets. Int J Pharm 219:113-126.

35. Berggren J, Alderborn G. 2001. Effect of drying rate on porosity and tabletting behaviour of cellulose pellets. Int J Pharm 227:81-96.

36. Chung TW, Huang YY, Liu YZ. 2001. Effect of the rate of solvent evaporation on the characteristics of drug loaded PLLA and PDLLA microsphere. Int J Pharm 212:161-169.

37. Kapsidou T, Nikolakakis I, Malamataris S. 2001. Agglomeration state and migration of drugs in wet granulation during drying. Int J Pharm 227:97112.

38. Alexandridis P. 1996. Amphiphilic copolymers and their applications. Curr Opin Colloid Interface Sci 1:490-501.

39. Alexandridis P. 1997. Poly(ethylene oxide)-poly (propylene oxide) block copolymer surfactants. Curr Opin Colloid Interface Sci 2:478-489.

40. Alexandridis P, Spontak RJ. 1999. Solvent-regulated ordering in block copolymers. Curr Opin Colloid Interface Sci 4:130-139.

41. Yang L, Alexandridis P. 2000. Controlled release from ordered microstructures formed by poloxamer block copolymers. ACS Symp Ser 752:364-374.

42. Ahmed F, Alexandridis P, Shankaran H, Neelamegham S. 2001. The ability of poloxamers to inhibit cell aggregation depends on their physicochemical properties. Thromb Haemost 86:15321539 . 
43. Chandaroy P, Sen A, Alexandridis P, Hui SW. 2002. Utilizing temperature-sensitive association of Pluronic F127 with lipid bilayers to control liposomecell adhesion. Biochim Biophys Acta 1559:32-42.

44. Alexandridis P, Zhou D, Khan A. 1996. Lyotropic liquid crystallinity in amphiphilic block copolymers: Temperature effects on phase behavior and structure of poly(ethylene oxide)- $b$-poly(propylene oxide)- $b$-poly(ethylene oxide) copolymers of different compositions. Langmuir 12:2690-2700.

45. Alexandridis P, Olsson U, Lindman B. 1997. Structural polymorphism of amphiphilic copolymers: Six lyotropic liquid crystalline and two solution phases in a polyoxybutylene- $b$-polyoxyethylene-waterxylene system. Langmuir 13:23-34.

46. Alexandridis P. 1998. Structural polymorphism of poly(ethylene oxide)-poly(propylene oxide) block copolymers in nonaqueous polar solvents. Macromolecules 31:6935-6942.

47. Alexandridis P, Lindman B, editors. 2000. Amphiphilic block copolymers: Self-assembly and applications. Amsterdam: Elsevier Science BV.

48. Moore T, Croy S, Mallapragada S, Pandit N. 2000. Experimental investigation and mathematical modeling of Pluronic ${ }^{\circledR}$ F127 gel dissolution: Drug release in stirred systems. J Control Release 67: 191-202.

49. Yang L, Talukdar SS, Alexandridis P. 2000. Physicochemical aspects of drug release from poloxamer block copolymer gels. Polym Prepr (Am Chem Soc Div Polym Chem) 41:1703-1704.

50. Anderson BC, Pandit NK, Mallapragada S. 2001. Understanding drug release from poly(ethylene oxide)- $b$-poly(propylene oxide)- $b$-poly(ethylene oxide) gels. J Control Release 70:157-167.

51. Lee MC, Peppas NA. 1993. Water transport in epoxy-resins. Prog Polym Sci 18:947-961.

52. Vrentas JS, Vrentas CM. 1994. Drying of solventcoated polymer films. J Polym Sci B Polym Phys 32:187-194.

53. Vrentas JS, Vrentas CM. 1998. Predictive methods for self-diffusion and mutual diffusion coefficients in polymer-solvent systems. Eur Polym J 34:797803.

54. Cairncross RA, Jeyadev S, Dunham RF, Evans K, Francis LF, Scriven LE. 1995. Modeling and design of an industrial dryer with convective and radiant heating. J Appl Polym Sci 58:1279-1290.

55. Ngui MO, Mallapragada S. 1998. Understanding isothermal semicrystalline polymer drying: Mathematical models and experimental characterization. J Polym Sci Part B Polym Phys 36:2771-2780.

56. Alsoy A, Duda JL. 1999. Modeling of multicomponent drying of polymer films. AIChE J 45:896905.

57. Alsoy A, Duda JL. 1999. Modeling of multilayer drying of polymer films. J Polym Sci Part B Polym Phys 37:1665-1675.
58. Price PE, Cairncross RA. 2000. Optimization of single-zone drying of polymer solution coatings using mathematical modeling. J Appl Polym Sci 78:149-165.

59. Wang BG, Yamaguchi T, Nakao SI. 2000. Solvent diffusion in amorphous glassy polymers. J Polym Sci Part B Polym Phys 38:846-856.

60. Romdhane IH, Price PE, Miller CA, Benson PT, Wang S. 2001. Drying of glassy polymer films. Ind Eng Chem Res 40:3065-3075.

61. Holmqvist P, Alexandridis P, Lindman B. 1997. Modification of the microstructure in poloxamer block copolymer-water oil systems by varying the oil type. Macromolecules 30:6788-6797.

62. Ivanova R, Lindman B, Alexandridis P. 2000. Evolution of the structural polymorphism of Pluronic F127 poly(ethylene oxide)-poly(propylene oxide) block copolymer in ternary systems with water and pharmaceutically acceptable organic solvents: From glycols to oils. Langmuir 16:9058-9069.

63. Ivanova R, Alexandridis P, Lindman B. 2001. Interaction of poloxamer block copolymers with cosolvents and surfactants. Colloids Surf A 183-185: 41-53.

64. Ivanova R, Lindman B, Alexandridis P. 2002. Effect of pharmaceutically acceptable glycols on the stability of the liquid crystalline gels formed by Poloxamer 407 in water. J Colloid Interface Sci 252:226-235.

65. O'Brien FEM. 1948. The control of humidity by saturated salt solutions. J Sci Instrum 25:73-76.

66. Greenspan L. 1977. Humidity fixed points of binary saturated aqueous solutions. J Res Natl Bur Stand A Phys Chem 81A:89-96.

67. Gu Z, Alexandridis P. 2004. Osmotic stress measurements of intermolecular forces in ordered assemblies formed by solvated block copolymers. Macromolecules 37:912-924.

68. Croll SG. 1986. Drying of latex paint. J Coating Technol 58:41-49.

69. Croll SG. 1987. Heat and mass transfer in latex paints during drying. J Coating Technol 59:81-92.

70. Keddie JL. 1997. Film formation of latex. Mater Sci Eng 21:101-170.

71. Steward PA, Hearn J, Wilkinson MC. 2000. An overview of polymer latex film formation and properties. Adv Colloid Interface Sci 86:195-267.

72. Guigner D, Fischer C, Holl Y. 2001. Film formation from concentrated reactive silicone emulsions. I. Drying mechanism. Langmuir 17:3598-3606.

73. McCabe WL, Smith JC, Harriot P. 2001. Unit operations of chemical engineering, 6th ed. New York: McGraw-Hill.

74. Malmsten M, Lindman B. 1992. Water self-diffusion in aqueous block copolymer solutions. Macromolecules 25:5446-5450.

75. Borodin O, Bedrov D, Smith GD. 2002. Concentration dependence of water dynamics in poly 
(ethylene oxide)/water solutions from molecular dynamics simulations. J Phys Chem B 106:51945199.

76. Beverley KJ, Clint JH, Fletcher PDI. 1999. Evaporation rates of pure liquids measured using a gravimetric technique. Phys Chem Chem Phys 1: 149-153.

77. Aranberri I, Beverley KJ, Blink BP, Clint JH, Fletcher PDI. 2002. How do emulsions evaporate? Langmuir 18:3471-3475.

78. Beverley KJ, Clint JH, Fletcher PDI. 2000. Evaporation rates of structured and non-structured liquid mixtures. Phys Chem Chem Phys 2:41734177.

79. Crank J. 1975. The mathematics of diffusion, 2nd ed. Oxford, UK: Clarendon Press.

80. Yang L, Alexandridis P. 1999. Mass transport in ordered microstructures formed by block copolymers: Ramifications for controlled release applications. Polym Prepr (Am Chem Soc Div Polym Chem) 40:349-350.

81. Yang L. September 2000. Microstructure, dynamics, and applications of solvated amphiphilic block copolymers [Doctor of Philosophy dissertation]. University at Buffalo.

82. Gillen KT, Douglas DC, Hoch JR. 1972. Selfdiffusion in liquid water to $-31^{\circ} \mathrm{C}$. J Chem Phys 57:5117-5119.

83. Anderson BC, Cox SM, Ambardekar AV, Mallapragada SK. 2002. The effect of salts on the micellization temperature of aqueous poly(ethylene oxide)- $b$-poly(propylene oxide)- $b$-poly(ethylene oxide) solutions and the dissolution rate and water diffusion coefficient in their corresponding gels. J Pharm Sci 91:180-188.

84. Wassall SR. 1996. Pulsed field-gradient-spin echo NMR studies of water diffusion in a phospholipid model membrane. Biophys J 71:2724-2732.

85. Srisiri W, Benedicto A, O'Brien DF, Trouard TP, Oradd G, Persson S, Lindblom G. 1998. Stabilization of a bicontinuous cubic phase from polymerizable monoacylglycerol and diacylglycerol. Langmuir 14:1921-1926.

86. McConville P, Pope JM. 2000. A comparison of water binding and mobility in contact lens hydrogels from NMR measurements of the water selfdiffusion coefficient. Polymer 41:9081-9088.

87. Blandin HP, David JC, Vergnaud JM, Illien JP, Malizewicz M. 1987. Modeling of drying of coatings: Effect of the thickness, temperature and concentration of solvent. Prog Org Coat 15:163-172.

88. Ion L, Vergnaud JM. 1995. Process of drying a polymeric paint by diffusion-evaporation and shrinkage: Determination of the concentrationdependent diffusivity. Polym Testing 14:479-487.

89. Talibuddin S, Runt J, Liu LZ, Chu B. 1998. Microstructure development and crystallization of poly (ethylene oxide) and melt-miscible PEO blends. Macromolecules 31:1627-1634.

90. Lisowski MS, Liu Q, Cho J, Runt J, Yeh F, Hsiao BS. 2000. Crystallization behavior of poly(ethylene oxide) and its blends using time-resolved wide- and small-angle X-ray scattering. Macromolecules 33: 4842-4849. 